\title{
Bilateral anatomical variation in branching pattern of external carotid artery in a male cadaver - a case report
}

\author{
KHANAL, L. ${ }^{1,2 *}$, BARAL, P. ${ }^{1,2}$, YADAV, P. ${ }^{1,2}$, PANDEYA, A. ${ }^{1,2}$, \\ SHAH, S. ${ }^{1,2}$ and KOIRALA, S. ${ }^{1,2}$
${ }^{1}$ Department of Human Anatomy, Bishweshwar Prasad Koirala Institute of Health Sciences - BPKIHS, P.O. Box 7053, Dharan, Nepal
${ }^{2}$ Department of Anatomy, Bishweshwar Prasad Koirala Institute of Health Sciences - BPKIHS, P.O. Box 7053, Dharan, Nepal
*E-mail: voicetolaxman@yahoo.co.in

\begin{abstract}
Developmental anomalies in the origin and branching pattern of the external carotid artery are not common. The level of the bifurcation of the common carotid artery and also the variations in the origin/branching pattern of the external carotid artery are well known and documented. During a routine dissection of middle aged male cadaver in department of Anatomy in BP Koirala Institute of Health Sciences (BPKIHS) The clinically-relevant variations to be noted were the high origin and anomalous course of the facial artery, superior thyroid artery arising as a branch of Common Carotid artery, high origin of ascending pharyngeal artery, posterior auricular artery and direct glandular branches to the Submandibular gland. Such anatomical variations of external carotid artery are important for surgeons in surgeries of head and neck region and also for radiologists in the image interpretation of the face and neck region.
\end{abstract}

Keywords: external carotid artery, anatomical variation, head and neck region, Submandibular gland.

\section{Introduction}

The common carotid arteries (CCA) provide the major source of blood to the head and neck. Normally, it gives two terminal branches, external and internal carotid arteries at the level of superior border of thyroid cartilage in carotid triangle (STANDRING, 2008). At its origin, it is in the carotid triangle and lies antero-medially to the internal carotid artery (ICA) (RAO and PRAKASHCHANDRA, 2011). External carotid artery (ECA) extends from the level of upper border of the lamina of thyroid cartilage to a point behind the neck of the mandible. During its course it gives altogether eight branches, of which the superficial temporal and maxillary arteries are its terminal branches (DATTA, 1989). ECA provides vascular supply to the structures of head and neck. Branches of ECA develop centripetally starting from the arterial network of that territory and the preferred routes are formed in accordance with the local hemodynamic need. This hemodynamic need may results in various types of variation in branching pattern of ECA (MAHENDRAKAR, 2007). The branches of ECA are the key landmarks for adequate exposure and appropriate placement of cross clamps on the carotid artery. So the knowledge of carotid system is useful to minimize the postoperative complications and in making bloodless surgical field (HAYASHI, HORI, OHTANI et al., 2005).

\section{Materials and Methods}

These anatomical variations were detected during dissection of head and neck region of a middle-aged male cadaver of Nepalese origin in the Department of Human Anatomy, B.P Koirala Institute Of Health Sciences (BPKIHS), Dharan, Nepal. The meticulous dissection of head and neck was carried out according to the instructions by Cunningham's Manual of
Practical Anatomy. The dissections took place during the year 2014. The body was preserved by the injection of a formalin based preservative ( $10 \%$ formalin) and stored at $-4^{\circ}$ centigrade in cold chamber prior to dissection. CCA and its terminal branches ECA\&ICA were identified on both sides. ECA and its branches were traced according to their landmarks to know whether the branching pattern was normal or variant.

\section{Case Report}

Bilateral variations in branching pattern were detected during the routine dissection in Laboratory Exercise (LABEX) session for 2nd year medical undergraduate students in Anatomy department in BPKIHS. Bifurcation of the common carotid artery was at the level of upper border of thyroid cartilage in both sides (Figures 1 and 2 ).

The first branch of the ECA, superior thyroid artery was originated from the common carotid artery directly $7 \mathrm{~mm}$ below the bifurcation on both sides. Left Facial artery was also found to be abnormal course, originating in digastrics triangle above the posterior belly of digastrics muscle $(4.2 \mathrm{~cm}$ from the point of bifurcation) and passing superficial to the Submandibular and finally found in the face region. Branch to the Submandibular gland from the left facial artery was also found to be absent. One additional branch was found, branched from the anterior aspect of left ECA, $2.9 \mathrm{~cm}$ from the point of bifurcation between the site of origin of lingual artery and facial artery. This unusual branch formed a loop pointing upward $(6 \mathrm{~mm})$ and coursed horizontally in anterior direction, then found to be entering inside the Submandibular gland and dividing into smaller branches supplying the gland (Figure 1). On the right side of neck ascending pharyngeal 
artery was found to be arising from the medial aspect of ECA above the lingual artery and below the facial artery, $2.2 \mathrm{~cm}$ from the point of bifurcation. Posterior auricular artery was also found to be arising unusually high, above the angle of mandible, $6.4 \mathrm{~cm}$ from the point of bifurcation. All other branches were normal in pattern (Figure 2).

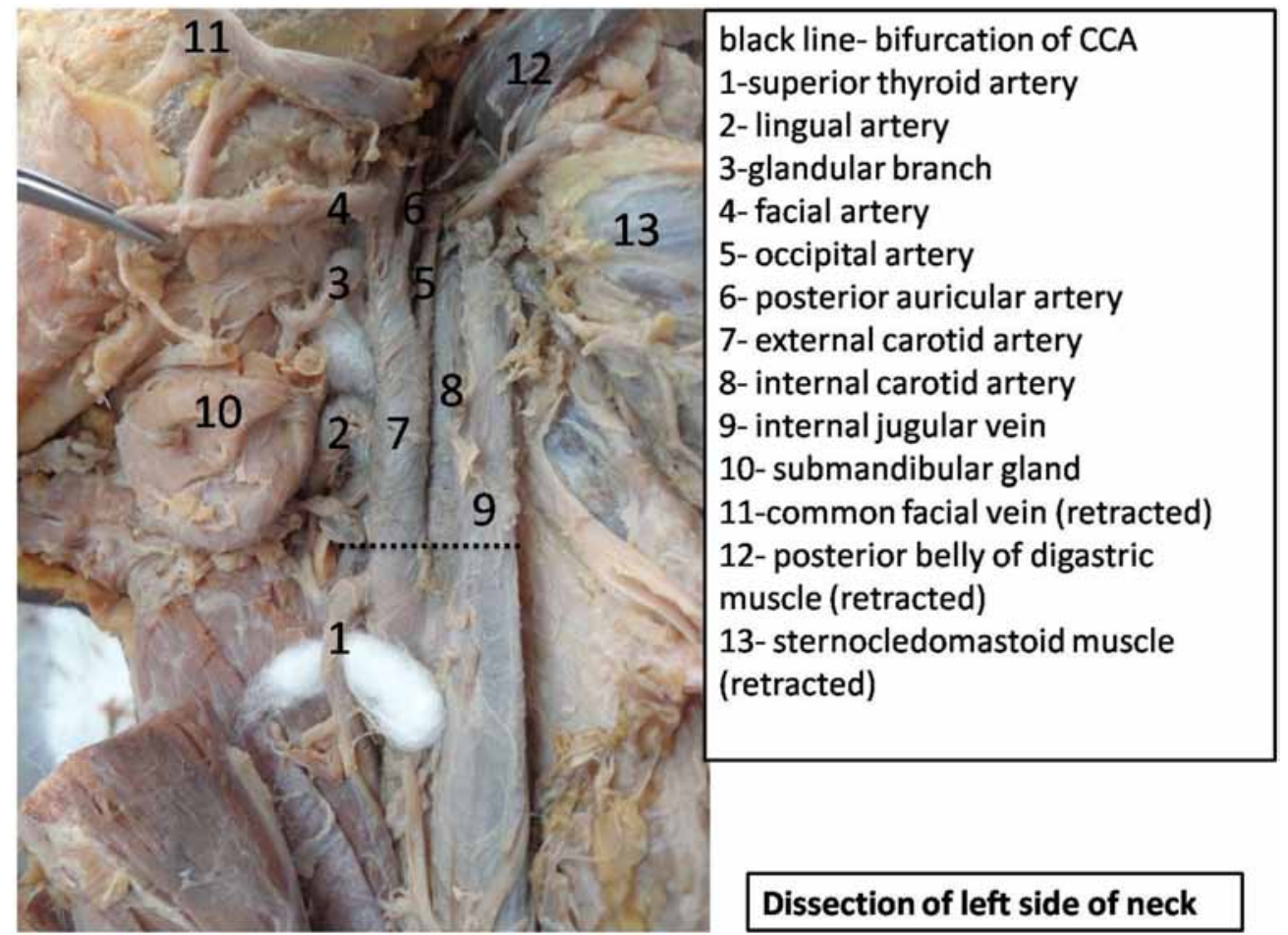

Figure 1. Dissection of left side of neck showing variations in branching pattern of External Carotid Artery.

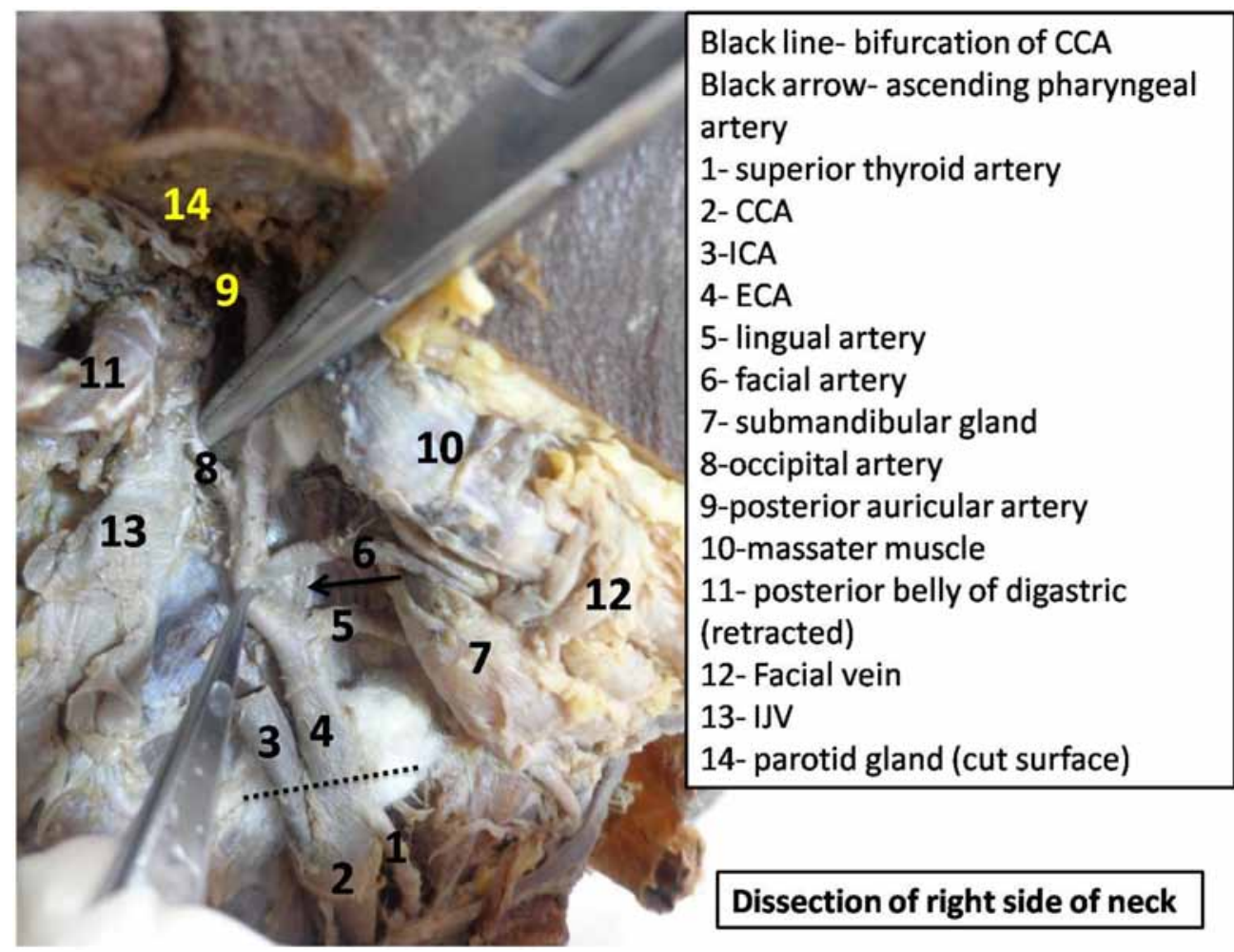

Figure 2. Dissection of right side of neck showing variations in branching pattern of External Carotid Artery. 


\section{Discussion}

Development of ECA is a complicated process of angiogenesis and remodeling which includes annexation and regression of vessels. The development of hyostapedial artery which links the neural crest arterial system to the ventral pharyngeal arterial system is an important event in the development of external carotid artery. Signals involved in annexation and regression are not always synchronized which results in various anatomical variations (LARSEN, 1998). Well known variations in branching pattern of carotid system are; common variations being superior thyroid, lingual and facial arteries arising from the common carotid artery, posterior auricular, maxillary and superficial temporal arteries originating from the common carotid artery by a common trunk and facial and lingual artery arises as common faciolingual trunk. In a cross sectional study done by Ik, Anita, Ashwini et al. (2010), among the 37 cadaver, the superior thyroid artery was found to arise from the common carotid in $35.14 \%$ of cases (KANEKO, AKITA, MURATA et al., 1996; KOIRALA and SHAH, 2012; SAVITHRI, 2012). A case report was found which showed an anomalous glandular branch arising directly from the ECA, on the medial aspect, $1.2 \mathrm{~cm}$ above the bifurcation of CCA. It exclusively supplied the Submandibular salivary gland (MAMATHA, RAJALAKSHMI, LATHA et al., 2010). A study done by Anu, Pai, Rajalakshmi et al. (2007) among the 95 cadavers a case was found to have glandular branches directly given off from the ECA to the parotid salivary gland. They also report about unusual origin and course of the right facial artery which arose from the ECA just above the angle of the mandible and passed directly on to the face crossing the posterior border of mandibular ramus and along the posterior pole of the superficial part of the Submandibular salivary gland. For reconstruction purposes, the Facial Artery Musculo-Mucosal (FAMM) flap was introduced. But its use is limited by variations in the course of the facial artery. Therefore, application of knowledge of the precise course and branching pattern of the facial artery is required for construction of FAMM flap and its successful utilization (PRIBAZ, STEPHENS, CRESPO et al., 1992; HIMA and RAO, 2012).

Acknowledgements: Authors want to thank all the members of department of Anatomy in BPKIHS who directly or indirectly helped us to accomplish this work by helping in lab work and guiding for dissection procedures.

\section{References}

ANU, VR., PAI, MM., RAJALAKSHMI, R., LATHA, VP., RAJANIGANDHA, V. and D'COSTA, SR. Clinically-relevant variations of the carotid arterial system. Singapore Medical Journal, 2007, vol. 48, n. 6, p. 566-569. PMid:17538758.
DATTA, AK. Essential of human anatomy: head, neck and brain. 2nd ed. New Delhi: IK International Publishing House, 1989. Available from: <http://books.google.com.np/books?id=tbuVAAAACAAJ>. Access in: 10 Aug. 2014.

HAYASHI, N., HORI, E. OHTANI, Y., OHTANI, O., KUWAYAMA, $\mathrm{N}$. and ENDO, S. Surgical anatomy of the cervical carotid artery for carotid endarterectomy. Neurologia Medico-Chirurgica, 2005, vol. 45 , n. 1, p. 25-29, discussion 30. http://dx.doi.org/10.2176/ nmc.45.25. PMid:15699617.

HIMA, BA. and RAO, BN. Abberant patterns of branching of external carotid artery. International Journal of Basic and Applied Medical Sciences, 2012, vol. 2, n. 2, p. 170-173.

IK, S., ANITA, H., ASHWINI, M., MAHESH, U. and RAIRAM, GB. Branching pattern of external carotid artery in human cadavers. Journal of Clinical and Diagnostic Research, 2010, vol. 4, p. 3128-3133.

KANEKO, K., AKITA, M., MURATA, E., IMAI, M. and SOWA, K. Unilateral anomalous left common carotid artery: a case report. Annals of Anatomy - Anatomischer Anzeiger, 1996, vol. 178, n. 5, p. 477-480. http://dx.doi.org/10.1016/S0940-9602(96)80147-6.

KOIRALA, S. and SHAH, S. Bilateral facio-lingual arterial trunk from external carotid artery: a case report. Webmed Journal, 2012, July. Available from: <http://www.webmedcentral.com/article_view/3533>. Access in: 10 Aug. 2014.

LARSEN, WJ. Human Embryology. 2nd ed. New York: Churchill Livingstone, 1998.

MAHENDRAKAR, MA. Variation in the branching pattern of external carotid artery: a case report. Journal of the Anatomical Society of India, 2007, vol. 56, n. 2, p. 47-51. Available from: <http://medind.nic. in/jae/t07/i2/jaet07i2p47.pdf>. Access in: 10 Aug. 2014.

MAMATHA, T., RAJALAKSHMI, R., LATHA, VP., GAVISHIDDAPPA, AH., JIJI, P. and PRAMEELA, MD. Anomalous branching pattern of the external carotid artery: a case report. Romanian Journal of Morphology and Embryology, 2010, vol. 51, n. 3, p. 593-595. PMid:20809046.

PRIBAZ, J., STEPHENS, W., CRESPO, L. and GIFFORD, G. A new intraoral flap: facial artery musculomucosal (famm) flap. Plastic and Reconstructive Surgery, 1992, vol. 90, n. 3, p. 421-429. http:// dx.doi.org/10.1097/00006534-199209000-00009. PMid:1513887.

RAO, TR. and PRAKASHCHANDRA, S. Unusual branching pattern of the external carotid artery in a cadaver. Chang Gung Medical Journal, 2011, vol. 34, n. 6, supplement, p. 24-27. PMid:22490454.

SAVITHRI, P. Unilateral variations in the branching pattern of right external carotid artery: a case report. National Journal of Clinical Anatomy, 2012, vol. 1, n. 3, p. 136-140. Available from: <http:// www.scopemed.org/?mno=24469>. Access in: 10 Aug. 2014.

STANDRING, S. Gray's Anatomy: the anatomical basis of clinical practice. 40th ed. London: Elsevier Churchill Livingstone, 2008. p. $444-447$.

Received August 10, 2014 Accepted September 2, 2015 